\title{
LNA-Modified Oligodeoxynucleotide Hybridization with DNA Microar- rays Printed on Nanoporous Membrane Slides
}

\author{
Jian-Ping Liu ${ }^{1,2}$, Anna Guerasimova ${ }^{1}$, Regine Schwartz ${ }^{1}$, Matthias Lange ${ }^{1}$, Hans Lehrach ${ }^{1}$, \\ Lajos Nyársik $^{1}$ and Michal Janitz ${ }^{*}, 1$ \\ ${ }^{1}$ Department of Vertebrate Genomics, Max-Planck-Institute for Molecular Genetics, D-14195 Berlin, Germany \\ ${ }^{2}$ Free University Berlin, Department of Biology, Chemistry and Pharmacy, D-14195 Berlin, Germany
}

\begin{abstract}
We report a robust method for the detection of hybridization events using a microarray-based assay on a nanoporous membrane platform. The technique is characterized by a hybridization time of only 1 hour and uses Cy5labeled, 7-mer oligodeoxynucleotide probes modified with locked nucleic acid (LNA) nucleotides. We show that the volume of the DNA spotted onto a nanomembrane can be reduced to $\sim 4 \mathrm{~nL}$ with detectable signal intensity. Moreover, the amount of the DNA target could be reduced to $4 \mathrm{fmol}$. The described approach could dramatically increase the throughput of techniques based on sequencing by hybridization, such as oligofingerprinting, by decreasing the total number of probes that are needed for analysis of large clone sets and reduction of the sample/reagent consumption. The method is particularly advantageous when numerous hybridization-based assays must be performed for characterization of sample sets of 100,000 or more.
\end{abstract}

Keywords: LNA, oligodeoxynucleotide, hybridization, microarray, nanoporous membrane, re-sequencing.

\section{INTRODUCTION}

DNA microarrays have helped to extract more information from smaller sample volumes and have become the method of choice for many hybridization-based assays, such as gene-expression profiling [1], single nucleotide polymorphism (SNP) genotyping [2], oligofingerprinting [3] and resequencing [4]. The construction of DNA microarrays involves immobilization or in situ synthesis of DNA targets or probes onto the specific sites of the substrate material. In this respect nylon-membrane-based DNA microarrays are a highly convenient and reliable method. Recent advances in the microarray substrates comprise development of supports with a nanoporous layer attached to the glass. Such substrates are cheaper and easier to handle. Moreover, they are superior to glass as the surface for DNA attachment, since they do not require chemical modifications and have a much higher capacity for DNA immobilization.

Large numbers of highly purified dsDNAs (e.g., 100,000 polymerase chain reaction (PCR) products) can be analyzed in parallel using sequence-specific hybridizations of very short oligodeoxynucleotides, such as 10-12-mers or even 79-mers [5]. Through 100-200 hybridizations of nucleotide probes with arrayed DNA libraries, the method of oligonucleotide fingerprinting (ONF) allows for identification of the patterns of gene expression [6] and generation of gene catalogues $[3,7]$. To further improve ONF analysis, it is highly desirable to reduce the total number of probes used for sequential hybridizations. This can be achieved by decreasing the length of the probes [8]. The reduction of probe length is,

*Address correspondence to this author at the Max-Planck-Institute for Molecular Genetics, Fabeckstrasse 60-62, D-14195 Berlin, Germany; Tel: +49 (30) 8413 1463; Fax: +49 (30) 8413 1462;

E-mail: janitz@molgen.mpg.de however, limited due to a low information content from hybridization of shorter probes and a decrease in the stability of the hybridization complex.

Insufficient stability and mismatch discrimination of conventional DNA oligodeoxynucleotides used for hybridization resulted in a growing interest in DNA analogues. In the case of 7-mer and 6-mer oligodeoxynucleotides, nucleic base modifications by locked nucleic acid (LNA) lead to stabilization of hybridization duplex formation and specificity of oligomer binding to DNA. LNA was introduced as a novel class of conformation-restricted oligodeoxynucleotide analogues [9]. It is a bicyclic nucleic acid in which a ribonucleoside is linked between the 2'-oxygen and the 4'-carbon atoms with a methylene unit. Due to the 'locked' structure that LNA displays, it has many advantageous properties, such as thermal stability of B-type duplexes, increased melting temperature, higher binding capacity to DNA and RNA $\left(\Delta T \mathrm{~m} /\right.$ modification $\left.=1-10^{\circ} \mathrm{C}\right)$, increased stability for $3^{\prime}-$ exonucleolytic degradation, robust mismatch discrimination and good aqueous solubility. The superior performance of LNAs has already been shown in SNP genotyping, expression profiling [10] and in situ hybridization [11]. In fact, LNA is recommended in any hybridization assay that requires high specificity and reproducibility [12].

The aim of this study was automation of hybridization and detection procedures with DNA arrays using fluorescence-based techniques and LNA-modified oligoprobes. We describe here the experimental set-up, in which LNAmodified 7-mer oligodeoxynucleotide probes are hybridized with PCR products of 1001-1661 bp in length, spotted onto a nanoporous membrane by non-contact printing. 


\section{MATERIALS AND METHODS}

\section{Preparation of Oligodeoxynucleotides}

DNA and DNA-LNA oligoprobes were synthesized by MWG Biotech (Ebersberg, Germany) and TIB MolBiol (Berlin, Germany). The sequences of probes used in this work are shown in Table 1. LNA synthesis followed standard amidite chemistry using Expedite 89020 DNA synthesizers and Hyacinth Activator. Cy5 was coupled to the 5'terminus using amidite chemistry. Deprotection was performed under mild conditions in ammonia. Ammonia was removed by Sephadex gelfiltration single use columns prior the HPLC-purification. HPLC buffer was removed by gel filtration and the amount of product was quantified based on the absorption at $260 \mathrm{~nm}$.

Table 1. Oligodeoxynucleotide Probes Used in the Study

\begin{tabular}{|c|c|}
\hline \multicolumn{2}{|c|}{ Oligonucleotide Probes } \\
\hline OP-1 & Cy5-TCAGAAG \\
\hline OP-1L & Cy5-TCA ${ }^{\#} \mathrm{GAA}^{\#} \mathrm{G}$ \\
\hline OP-2 & Cy5-CTGAAGC \\
\hline $\mathrm{OP}-2 \mathrm{~A}$ & Cy5-CT ${ }^{\#}$ GAAGC \\
\hline OP-2B & Су5-C"TGAAG ${ }^{\#} \mathrm{C}$ \\
\hline $\mathrm{OP}-2 \mathrm{C}$ & $\mathrm{Cy} 5-\mathrm{CT}^{\#} \mathrm{G}^{\#} \mathrm{AAG}^{\#} \mathrm{C}$ \\
\hline OP-2D & $\mathrm{Cy} 5-\mathrm{CT}^{\#} \mathrm{G}^{\#} \mathrm{~A} \mathrm{~A}^{\#} \mathrm{G}^{\#} \mathrm{C}$ \\
\hline OP-2E & Cy5-CT $\mathrm{T}^{\#} \mathrm{G}^{\#} \mathrm{~A}^{\#} \mathrm{~A}^{\#} \mathrm{G}^{\#} \mathrm{C}$ \\
\hline $\mathrm{OP}-3$ & Cy5-ATGAGGA \\
\hline OP-3L & Cy5-AT $\mathrm{GA}^{\#} \mathrm{GG}^{\#} \mathrm{~A}$ \\
\hline OP-4L & Cy5-C"TGAAG ${ }^{\#} \mathrm{G}$ \\
\hline OP-5L & Cy5-T $\mathrm{T}^{\#} \mathrm{GCT}^{\#} \mathrm{GG}^{\#} \mathrm{G}$ \\
\hline OP-6L & Су5-TT" CCTCC \\
\hline
\end{tabular}

\section{Target Preparation}

One of the templates used in this study was synthetic, single-stranded DNA (ssDNA), 22 bp in length (5'CAGGGCAGGTTTGCTTCAGTTT-3'), complementary to the oligoprobe sequences. In another set of experiments, eight sequence-verified double stranded DNA (dsDNA) clones (dsDNA-1 to dsDNA-8) were used with a size range between 1001 and $1661 \mathrm{bp}$. All the clones were derived from the human chromosome Xq28 cosmid clone (GeneBank accession number: AL034384). The dsDNA target sequences matched the cosmid fragment at the positions 100248101341 (dsDNA-1), 131072-132072 (dsDNA-2), 100143101405 (dsDNA-3), 130867-132210 (dsDNA-4), 130350132010 (dsDNA-5), 101189-102447 (dsDNA-6), 130879132115 (dsDNA-7) and 100850-101936 (dsDNA-8), respectively. Plasmid inserts were amplified using particular clones, as described previously [13]. Concentrations of the ethanol-precipitated PCR products were measured using a Bio-Photometer (Eppendorf, Hamburg, Germany) and then adjusted to the desired concentration range (from 0.1 to 0.4 $\mu \mathrm{M})$. Samples were transferred into 96-well plates, which were sealed and stored at $-20^{\circ} \mathrm{C}$ until further use for spotting.

\section{Microarray Construction}

Protocols for microarray preparation were modified from the 'instruction for use', available at http://www.pall.com/ pdf/1193_87485B.pdf. Briefly, target DNA samples that had been dissolved in TE buffer were spotted onto the Vivid Pall membrane slides with a printable area of $60 \mathrm{~mm} \times 20 \mathrm{~mm}$ (Pall Corporation, East Hills, NY) using a piezoelectric pipette spotting robot (SciFlexArrayer, Scienion, Berlin, Germany). The system was programmed to release about 4-40 nL DNA of solution for each DNA spot. Spots were arrayed in a $10 \times 10$ arrangement $(100$ spots in a $1.2 \times 1.2 \mathrm{~cm}$ area $)$ with a center-to-center distance between spots of 500-1000 $\mu \mathrm{m}$. Each DNA target was printed in duplicate. After deposition, DNA spots were completely dried by incubation on a thermal block at $96^{\circ} \mathrm{C}$ for $5 \mathrm{~min}$. DNA was then cross-linked by ultraviolet irradiation using a Stratalinker ${ }^{\mathrm{TM}}$ oven (Stratagene, La Jolla, CA) that was set at $1200 \mathrm{~mJ}$. Blocking of the non-reacted surface was achieved by incubating the slides at $4{ }^{\circ} \mathrm{C}$ for at least $30 \mathrm{~min}$ in a solution of $3 \%(\mathrm{w} / \mathrm{v})$ casein-hammerstein, $150 \mathrm{mM} \mathrm{NaCl}, 10 \mathrm{mM}$ Tris pH 8.0 adjusted using $\mathrm{HCl}$, and $1 \%(\mathrm{w} / \mathrm{v})$ SDS (sodium dodecyl sulfate), followed by incubation in a washing buffer $(50 \mathrm{mM}$ $\mathrm{NaCl}, 20 \mathrm{mM}$ Tris $\mathrm{pH} 7.4$ adjusted using $\mathrm{HCl}$ and $0.2 \%$ (v/v) Tween 20) by gentle shaking at $4^{\circ} \mathrm{C}$ for about $10 \mathrm{~min}$. The slides were then air-dried and stored at $4^{\circ} \mathrm{C}$.

\section{Membrane Slide Hybridization}

Before hybridization, the arrays were pre-hybridized for $30 \mathrm{~min}$ at room temperature with hybridization buffer (100 $\mathrm{mM} \mathrm{NaCl}, 40 \mathrm{mM}$ Tris $\mathrm{pH} 7.4$ adjusted using $\mathrm{HCl}$ and $0.2 \%$ (v/v) Tween 20). A total of 200 pmol of Cy5-labeled oligoprobe was added to $20 \mathrm{~mL}$ of hybridization buffer in a plastic or glass box and then denatured at $98^{\circ} \mathrm{C}$ for $5 \mathrm{~min}$. The membrane slides were incubated in the boiling hybridization solution for 5 min with gentle shaking and then cooled down on ice, followed by washing with hybridization buffer at $4^{\circ} \mathrm{C}$ for $5 \mathrm{~min}$.

\section{Stripping Procedure}

The oligoprobe was removed by incubation of the membrane in stripping buffer $(100 \mathrm{mM} \mathrm{NaCl}, 40 \mathrm{mM}$ Tris $\mathrm{pH} 7.4$ adjusted using $\mathrm{HCl}, 0.2 \%(\mathrm{v} / \mathrm{v})$ Tween $20,0.4 \times \mathrm{SSC} \mathrm{pH} 7.5$ (adjusted using tri-sodium citrate dihydrate and sodium chloride), $0.2 \%(\mathrm{w} / \mathrm{v}) \mathrm{SDS}$ ) at $80^{\circ} \mathrm{C}$ for $30 \mathrm{~min}$ when the LNAmodified oligoprobes were used. In cases in which nonmodified oligoprobes were used, a period of 10 min incubation in stripping buffer was applied. Subsequently, the slides submerged in hybridization buffer were cooled down to room temperature. The membranes were verified using a charge-coupled-device (CCD) camera to ensure that all Cy5 fluorescence had been removed. Once the fluorescent intensity had been eliminated, dried membranes were stored at room temperature.

\section{Microarray Image Acquisition and Data Analysis}

For hybridization signal imaging, we used the 16-bit CCD-camera type CH350 (Photometrix, Tucson, AZ, USA), with the $512 \times 512$ pixel chip size cooled down to $-40^{\circ} \mathrm{C}$. The camera allowed the measurement of pixel values in the range from 0 to 65535 . The acquired pixel values were cor- 
rected for background and presented as arbitrary units of fluorescence intensity. The CCD-camera was operated by software that had been developed in-house. An object field of $20 \times 20 \mathrm{~mm}^{2}$ could be detected using this approach. The excitation light was generated by a halogen light source with an interference filter. The emission filter was placed directly on the front side of the camera objective. For excitation, a $620 \mathrm{~nm}$ filter (AHF, Tübingen, Germany) was used; for emission, a $670 \mathrm{~nm}$ filter (Andover Corporation, Salem, NH, USA) was used.

For signal quantification, the images were evaluated using AlphaEaseFC ${ }^{\mathrm{TM}}$ Software version 4.0.0 (Alpha Innotech Corporation, San Leandro, CA, USA). The intensity for each spot was calculated by integrating the gray scale values within the spot and subtracting the local background. Deviating spots (e.g. high background, dust, irregularities, etc.) were manually removed from the analysis. The mean background-corrected spot intensity of each sample was used in subsequent data analysis, as described previously [14].

\section{RESULTS AND DISCUSSION}

\section{DNA Array Generation}

Our aim was to apply a nanoporous membrane for fluorescence-based high-throughput hybridization assays. Threedimensional nanoporous substrates offer a higher amount of potential immobilization space than does modified glass. Therefore, larger amounts of DNA can be applied to the membrane, resulting in stronger signal intensities and a better signal dynamic range. Hence, more consistent data than the 'two-dimensional' surface can be delivered [15]. Furthermore, strong attachment to the membrane leads to better retention of the arrayed DNA, resulting in a higher concentration of DNA per spot than on glass.

In our studies, the experimental verification of this concept was carried out using Pall Life Science Gene Array Slides (East Hills, NY, USA), in which a soft nanomembrane layer is bound to a glass substrate, in the format of a microscopic slide $\left(75 \times 25 \mathrm{~mm}^{2}\right)$. The Pall hybridization membrane is a positively charged nanoporous membrane for rapid ionic binding of nucleic acids and is widely applied to macro- and micro-arrays. Previously published analysis of the hybridization signals demonstrated that the Pall nanoporous membrane delivers the highest signal-to-noise ratio compared to Amersham Hybond $\mathrm{N}+$, Schleider \& Schuell Nitran supercharged and Boehringer Nylon membranes [16].

Regarding microarray preparation, a standard pin-based spotting technology cannot be applied, as the nanomebrane layer becomes damaged in the course of the spotting process. This, in turn, can influence the probe binding capacity and hybridization signal properties. We have implemented a piezo-dispensing system (FlexArrayer, Scienion, Berlin, Germany) for non-contact dispensing of samples onto the membrane slides. Without mechanical contact to the surface, we achieved a homogeneous spot distribution throughout the membrane. The spot size can be defined by the number of droplets applied to a particular position. With the use of piezo-capillaries with a 50- $\mu \mathrm{m}$ orifice, the droplet resolution of $200 \mathrm{pL}$ could be achieved, although the final droplet volume that was used for spotting was $1-100 \mathrm{~nL}$.

\section{Comparison of DNA and LNA-Modified Oligoprobes}

Hybridization of LNA-modified, 7-mer oligodeoxynucleotides (listed in Table 1) with the arrayed double-stranded (ds) DNA resulted in significantly higher hybridization signal than that derived from hybridization with the respective non-modified DNA oligodeoxynucleotides (Fig. 1A). We examined the influence of number of LNA modifications on the hybridization signal intensity and determined that more than two LNA modifications per oligoprobe resulted in deterioration of the signal. The higher number of modifications did, indeed, lead to a stronger signal; this was, however, accompanied by an increase in non-specific oligoprobe binding. In our experimental conditions, 7-mer oligodeoxynucleotides with more than two LNA modifications exhibited a much higher rate of false-positives (Fig. 1B). This behaviour can probably be attributed to the high affinity of LNA to DNA. One of the most important features of LNA-modified oligodeoxynucleotides is high thermal stability of their duplexes with complementary DNA or RNA. Insertion of a single LNA base into oligodeoxynucleotide can elevate its Tm by ca. $10^{\circ} \mathrm{C}$. This effect is most profound for oligomers below 10 bp [17]. 7-mer oligodeoxynucleotides with more than two LNA modifications bind more tightly to the DNA target. For such probes it is therefore difficult to precisely discriminate between true positives and unspecific binding under the short washing time and moderate washing conditions used in this study. As a consequence of this observation, we used only two LNA modifications per oligodeoxynucleotide probe in further experiments.

\section{Limitations of the Signal Detection and Signal Linearity}

Although the minimum dispensing volume of the SciFlexArrayer is $100 \mathrm{pL}$, the amount of DNA spotted in $\mathrm{pL}$ volume remained below the signal detection limit (data not shown). In this study, the volume of DNA solution at the concentration of $1 \mu \mathrm{M}$ could be scaled down to about $20 \mathrm{~nL}$ or even $4 \mathrm{~nL}$ (Fig. 2A). These volumes correspond to the immobilized DNA amounts as low as 20 and $4 \mathrm{fmol}$, respectively. Despite such low amounts of target DNA immobilized on the membrane, the hybridization signals were still distinguishable, thus making miniaturization towards operating nanoliter volumes feasible. Taken together, the detection limit in our system was found to be $4 \mathrm{~nL}$ of the droplet volume (Fig. 2A), containing 4 fmol of the target DNA.

\section{Re-Utilization of the Membrane Slide}

The degree to which a nanoporous membrane binds and retains arrayed DNA after subsequent stripping cycles is an important economic aspect of the membrane array utility. Hence, the number of cycles of membrane stripping and reprobing that can be performed without significant decreases in hybridization signal quality is one of the crucial selection criteria when considering a membrane substrate for highthroughput applications. In our study, Pall VIVID membrane slides could be successfully stripped and re-probed at least 19 times without significant loss of signal intensity (Fig. 2B). The slides can be stored at room temperature and used for at least 6 months, without significant reduction in signal quality (data not shown). Another important parameter for high-throughput applications is the cycling time when reusing the slides. We have shortened the hybridization proto- 
A.

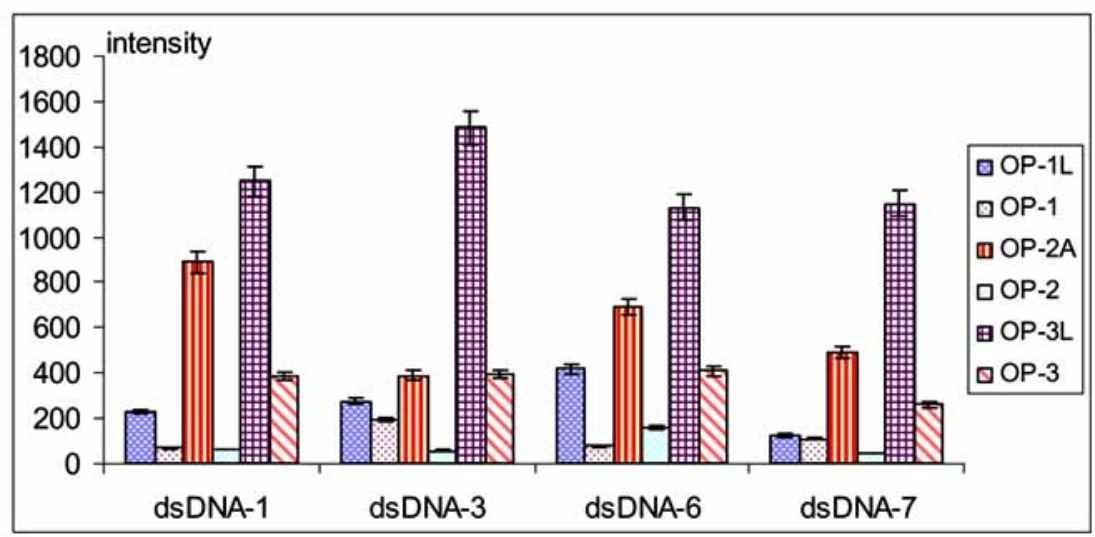

B.
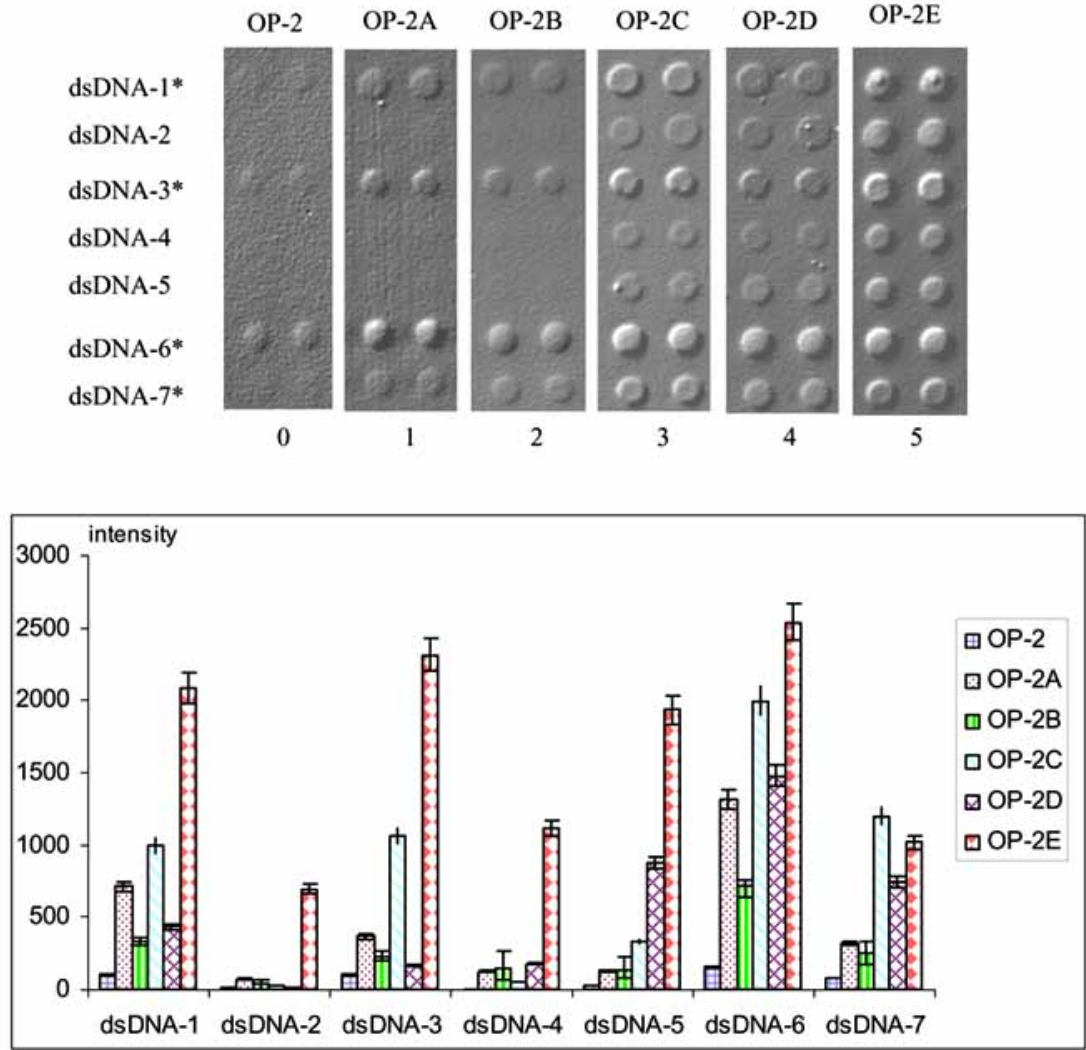

Fig. (1). (A) Hybridization comparison of LNA- with DNA-oligodeoxynucleotides using double-stranded (ds) DNA as templates. 100 droplets $(40 \mathrm{~nL})$ of $0.3 \mu \mathrm{M}$ dsDNAs (dsDNA-1, -3, -6, -7) were spotted in duplicates onto porous membrane and hybridized with 7-mer LNAmodified oligodeoxynucleotides (OP-1, -1L, -2, -2A, -3, -3L), respectively. The background was subtracted. (B) The effect of different LNA modifications on hybridization efficiency. 100 droplets $(40 \mathrm{~nL})$ of $0.4 \mu \mathrm{M}$ dsDNAs (dsDNA-1 to dsDNA-7) were spotted in duplicates onto nylon membranes and then hybridized with OP-2 with different LNA modifications (OP-2, OP-2A-E). The numbers under the images show the LNA modification number. The images show the hybridization signal from seven dsDNAs, of which four (dsDNA-1, $-3,-6$ and -7 , indicated by asterisk) match to OP-2, whereas the other three (dsDNA-2, -4 and -5 ) do not. The background was subtracted. The hybridization signals were quantified as shown in the diagram at the bottom side. Data were plotted as a mean and SD from three independent experiments. Fluorescence intensity was presented in arbitrary units as described in Materials and Methods.

col to less than $60 \mathrm{~min}$. The hybridization step itself is a rapid process (30 min vs. 3-16 $\mathrm{h}$ in the classical approach), and could be potentially shortened further by the use of a micro-fluidic chamber. Furthermore, the solid slide format is an important factor for subsequent automation of the process giving a possibility of mounting the nano-membrane slide into a micro-chamber device. 


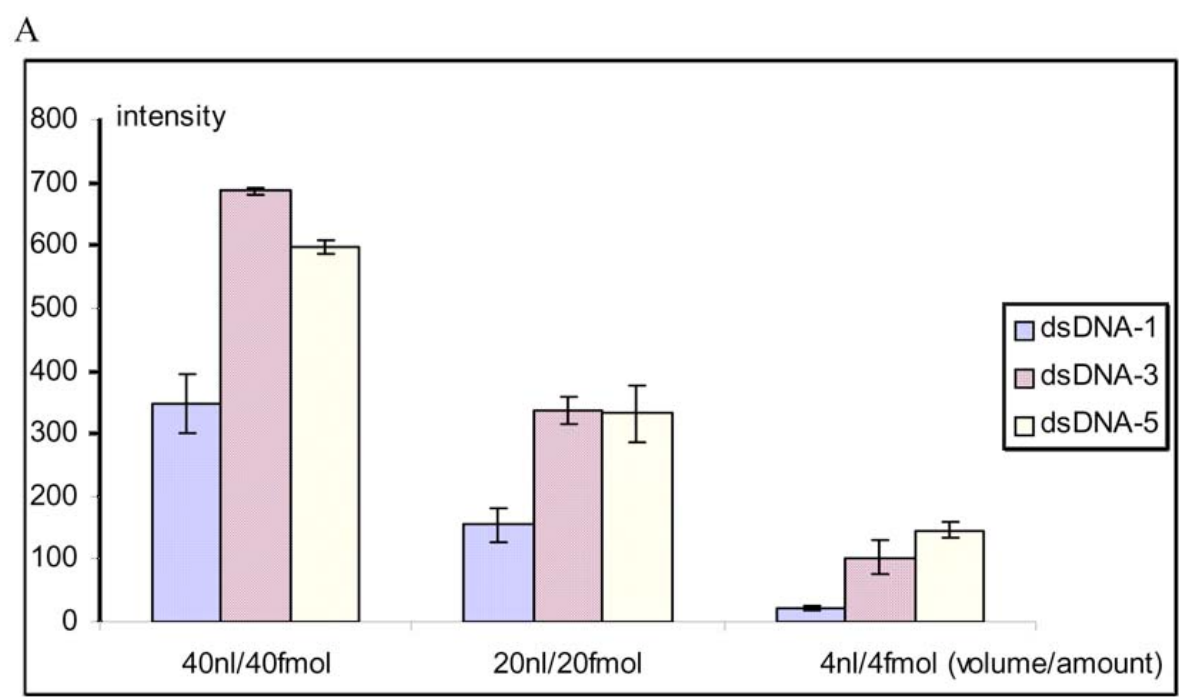

B

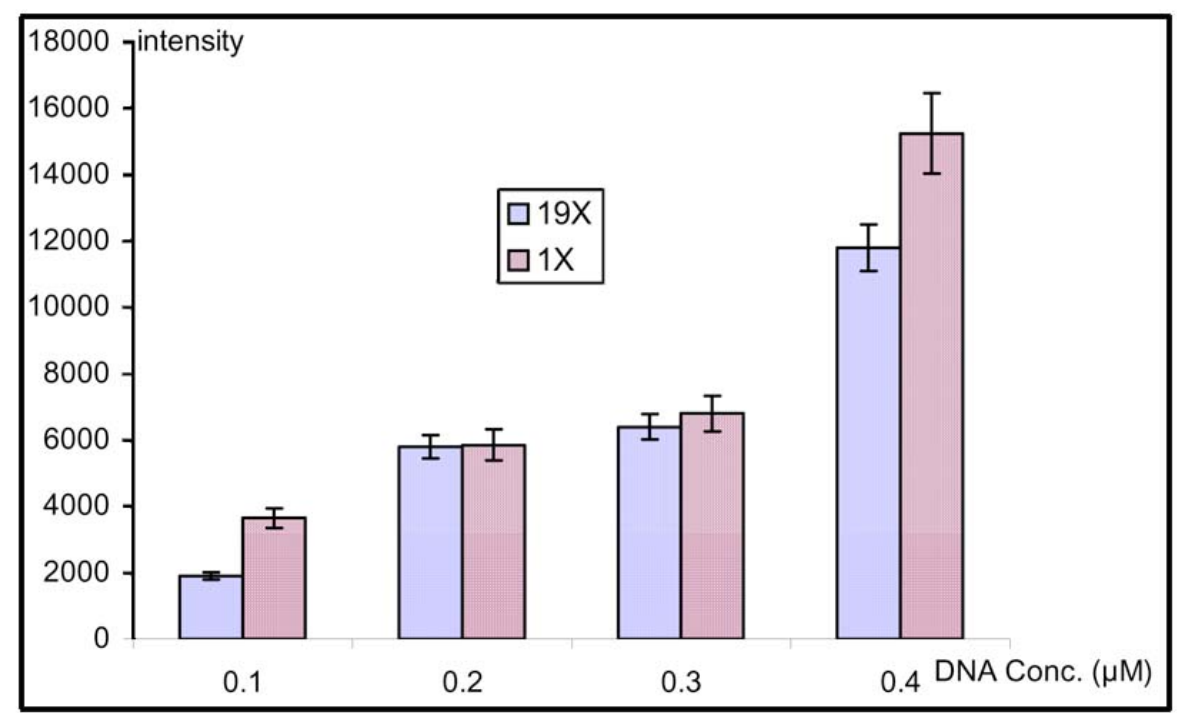

Fig. (2). (A) Determination of signal detection limit and signal linearity. Three dsDNAs (dsDNA-1, -3 and -5 ) at a concentration of $1 \mu \mathrm{M}$ were dispensed in duplicates onto the porous membrane with a different number of droplets (i.e. 100 droplets, 50 droplets and 10 droplets), and then hybridized with OP-3L. Data were plotted as a mean and SD from three independent experiments. (B) Re-utilization of the membrane slide. A total of 100 droplets $(40 \mathrm{~nL})$ of single-stranded DNA at concentrations of $0.1-0.4 \mu \mathrm{M}$ was spotted onto the membrane slide and then hybridized with full-match OP-4L. The signal intensities following hybridization with the same membrane for single oligodeoxynucleotide stripping (indicated as $1 \times$ ) and for 19 stripping rounds (indicated as $19 \times$ ) are presented. Data were plotted as a mean and SD from three independent experiments. Fluorescence intensity was presented in arbitrary units as described in Materials and Methods.

\section{Model Verification - The Example of Oligofingerprint- ing}

In a classical protocol of oligofingerprinting, PCR products are spotted on the nylon membrane and hybridized with radioactively labeled oligoprobes [18]. The method has been further modified by using fluorescence detection and application of PNA-modified oligoprobes [19]. Recently, the induced fluorescence resonance energy transfer-based signal detection in solution with LNA-modified DNA probes has been reported [14].
The principle of ONF relies on the establishment of DNA-specific patterns of hybridization with a set of oligoprobes of defined length so that similar dsDNA clones can be grouped into the sequence clusters. It has been shown that reduction of the probe length results in a reduced number of hybridizations necessary for production of the unique fingerprint. For example, only 507 -mer probes are theoretically required to deliver the same sequence information on particular DNA clones, whereas application of the 8-mer probes requires using 220 oligodeoxynucleotides [18]. Reduction of the number of hybridizations results, in turn, in a drastic reduction of costs in terms of reagents and time consumption. 
A

\begin{tabular}{|c|c|c|c|c|c|c|c|c|}
\hline & OP-1L & & OP-4L & & OP-5L & & OP-6L & \\
\hline dsDNA-1 & 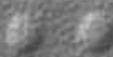 & & & + & (c) 8 & + & & + \\
\hline dsDNA-2 & 42 & & & & & & & t \\
\hline dsDNA-3 & 6793 & & S8 & + & 98 & + & & + \\
\hline dsDNA-4 & 7) 15 & & & - & f.5 & + & 6. 5 & + \\
\hline dsDNA-5 & 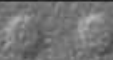 & & & - & 89 & + & (2) & + \\
\hline dsDNA-6 & 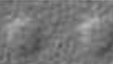 & & 8 & + & 20 & + & & - \\
\hline dsDNA-7 & tos & & & + & E 8 & + & 4 & + \\
\hline & 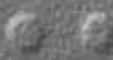 & & & & ce & & () & + \\
\hline
\end{tabular}

B

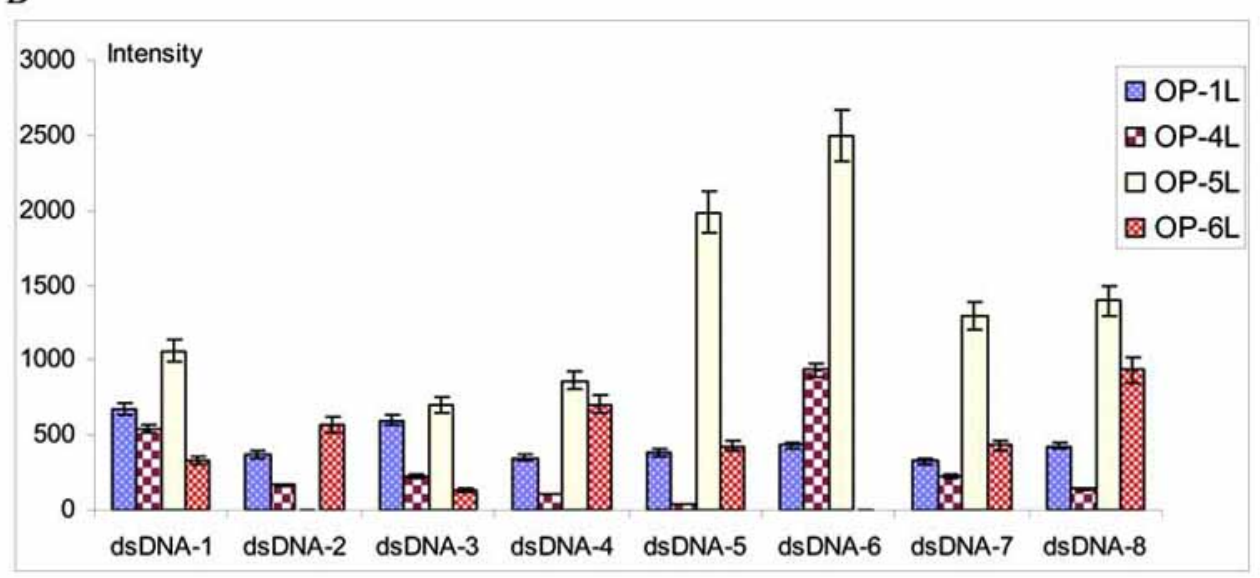

Fig. (3). Model oligofingerprinting for eight dsDNA clones using four LNA probes. (A) A total of 100 droplets (40 nL) of eight dsDNAs (dsDNA-1 to -8) at a concentration of $0.4 \mu \mathrm{M}$, were spotted in duplicates onto nanoporous membranes, denatured and hybridized with four LNA-modified 7-mer oligodeoxynucleotides (OP-1L, OP-4L, OP-5L and OP-6L). Sequence match between the oligodeoxynucleotide and the dsDNA was indicated as + , and no match as - . The images were acquired by charge-coupled-device camera after a single washing of the membranes. (B) Quantification of hybridization signal intensities. The background was subtracted. Data were plotted as a mean and SD from three independent experiments. Fluorescence intensity was presented in arbitrary units as described in Materials and Methods.

Here, we show for the first time that hybridization of as short as 7 -mer probes can be reliably used for DNA sequence characterization. Fig. 3 shows an example of sequencespecific signatures for eight clones with four probes. It is clear that the dynamic range of signal varies (e.g. OP-1L vs. OP-5L in Fig. 3), so there is still demand for setting a threshold to distinguish between 'positive' and 'negative' hybridizations. Nevertheless, the positive signals are clearly distinguishable from the negative ones.

In the present study, we showed that a DNA hybridization platform based on membrane-covered slides allows inherent limitations of standard arrays on glass slides to be overcome - such as low binding capacity, low signal level, limited re-utilization of the arrays and long processing time. The application of LNA-modified oligodeoxynucleotides improved the hybridization sensitivity, thereby allowing us- age of shorter, and therefore less, oligoprobes for dsDNA characterization.

\section{ACKNOWLEDGEMENTS}

Sequence-verified DNA clones were kindly provided by the RZPD Deutsches Ressourcenzentrum für Genomforschung, Germany. This work was supported by the European Commission project MolTools and the Max-Planck-Society.

\section{REFERENCES}

[1] Valk, P.J.; Verhaak, R.G.; Beijen, M.A.; Erpelinck, C.A.; Barjesteh van Waalwijk van Doorn-Khosrovani, S.; Boer, J.M.; Beverloo, H.B.; Moorhouse, M.J.; van der Spek, P.J.; Lowenberg, B.; Delwel, R. N. Engl. J. Med., 2004, 350, 1617.

[2] Dumur, C.I.; Dechsukhum, C.; Ware, J.L.; Cofield, S.S.; Best, A.M.; Wilkinson, D.S.; Garrett, C.T.; Ferreira-Gonzalez, A. $\underline{G e-}$ nomics, 2003, 81, 260. 
[3] Meier-Ewert, S.; Lange, J.; Gerst, H.; Herwig, R.; Schmitt, A.; Freund, J.; Elge, T.; Mott, R.; Herrmann, B.; Lehrach, H. Nucleic Acids Res., 1998, 26, 2216.

[4] Shendure, J.; Mitra, R.D.; Varma, C.; Church, G.M. Nat. Rev. Genet., 2004, 5, 335.

[5] Beier, M.; Hoheisel, J.D. Nucleic Acids Res., 1999, 27, 1970.

[6] Gress, T.M.; Hoheisel, J.D.; Lennon, G.G.; Zehetner, G.; Lehrach, H. Mamm. Genomes, 1992, 3, 609.

[7] Panopoulou, G.; Hennig, S.; Groth, D.; Krause, A.; Poustka, A.J.; Herwig, R.; Vingron, M.; Lehrach, H. Genome Res., 2003, 13, 1056.

[8] $\quad \overline{H e r w i g, ~ R . ; ~ S c h m i t t, ~ A . O . ; ~ S t e i n f a t h, ~ M . ; ~ O ' B r i e n, ~ J . ; ~ S e i d e l, ~ H . ; ~}$ Meier-Ewert, S.; Lehrach, H.; Radelof, U. Bioinformatics, 2000, $16,890$.

[9] Kumar, R.; Singh, S.K.; Koshkin, A.A.; Rajwanshi, V.K.; Meldgaard, M.; Wengel, J. Bioorg. Med. Chem. Lett., 1998, 8, 2219.

[10] Kloostermann, W.P.; Wienholds, E.; de Bruijn, E.; Kauppinen, S.; Plasterk, R.H.A. Nat. Methods, 2005, 3, 27.
[11] Vester, B.; Wengel, J. Biochemistry, 2004, 43,13233.

[12] http://www.linktech.co.uk/lna.htm

[13] Bauer, O.; Guerasimova, A.; Sauer, S.; Thamm, S.; Steinfath, M.; Herwig, H.; Janitz, M.; Lehrach, H.; Radelof, U. Rapid Commun. Mass Spectrom., 2004, 18, 1821.

[14] Guerasimova, A.; Nyarsik, L.; Liu, J.P.; Schwartz, R.; Lange, M.; Lehrach, H.; Janitz, M. Biomol. Eng., 2006, 23, 35.

[15] Stillman, B.A.; Tonkinson, J.L. Anal. Biochem., 2001, 295, 157.

[16] Alberola, T.M.; Garcia-Martinez, J.; Antunez, O.; Viladevall, L.; Barcelo, A.; Arino, J.; Perez-Ortin, J.E. Int. Microbiol., 2004, 7, 199.

[17] Braasch, D.A.; Corey, D.R. Chem. Biol., 2001, $8,1$.

[18] Herwig, R.; Schulz, B.; Weisshaar, B.; Hennig, S.; Steinfath, M.; Drungowski, M.; Stahl, D.; Wruck, W.; Menze, A.; O'Brien, J.; Lehrach, H.; Radelof, U. Plant J., 2002, 32, 845.

[19] Guerasimova, A.; Nyarsik, L.; Girnus, I.; Steinfath, M.; Wruck, W.; Griffiths, H.; Herwig, R.; Wierling, C.; O'Brien, J.; Eickhoff, H.; Lehrach, H.; Radelof, U. Biotechniques, 2001, 31, 490. 